\title{
Assessment Estimate Anticipated Indicator
}

National Cancer Institute

\section{Source}

National Cancer Institute. Assessment Estimate Anticipated Indicator. NCI Thesaurus.

Code C93512.

Specifies whether an assessment is an estimate. 